\title{
Abiotic Stresses Tolerance and Nutrients Contents in Groundnut, Pearl Millet and Sorghum Mini Core Germplasm for Food and Nutrition Security
}

\author{
Hamidou Falalou ${ }^{1,2}$, Awel M Sani ${ }^{1}$, Bissala Y Hassane ${ }^{1}$, Achirou B Falke ${ }^{1}$ and Hari D Upadhyaya ${ }^{3}$ \\ ${ }^{1}$ International Crops Research Institute for the Semi-Arid Tropics (ICRISAT), Sahelian Center, \\ BP 12404, Niamey, Niger \\ ${ }^{2}$ Department of Biology, Faculty of Sciences and Techniques, University Abdou Moumouni, Niamey, Niger \\ ${ }^{3}$ International Crops Research Institute for the Semi-Arid Tropics, Patancheru-502324, Telangana, India
}

\begin{abstract}
Groundnut, pearl millet and sorghum germplasm were investigated to identify new sources of tolerance to low phosphorus (LP) and/or drought stress (WS) and to assess genotypic variation for iron (Fe) and zinc ( $\mathrm{Zn}$ ) contents. Experiments were conducted in lysimetre conditions in a randomized completely block design with 5 replications, 2 water and 2 phosphorus treatments. Genotypic variability was observed for morphoagronomic and nutrients traits investigated. Groundnut accessions ICG 3312, ICG 11855, ICG 10053, ICG 15232 and ICG 11088 revealed drought tolerant. The combined WS-LP effect (73\%) was higher than individual WS (68\%) and LP (49\%) effects. LP significantly delayed heading and flowering dates, accessions IP1060, IP11405 and IP9000 (millet), and ISS1412, ISS2167, ISS376 and ISS738 (sorghum) showed less delay and LP tolerance. Fe and Zn contents under LP showed that accessions IP17775, IP5581, IP5153, IP1060, IP6517 and IP5438 of millet; ISS376, ISS1412, ISS2167, ISS242, ISS311 and ISS2151 of sorghum revealed high Fe and/or Zn concentrations.
\end{abstract}

Key Words: Crop improvement, Drought tolerance, Low phosphorus, Mini core collections, Nutrients contents

\section{Introduction}

Sustainable agriculture and malnutrition challenges require the use of genotypes tolerant to abiotic stress and highly rich in micronutrients. Detailed evaluation and characterization of materials conserved in genebanks could lead to select these genotypes. Mini core collections of groundnut, pearl millet and sorghum (Upadhyaya et al., 2002; Upadhyaya et al., 2009; Upadhyaya et al., 2011), representing diversity of global collections, are ideal material for extensive evaluation to select new crop varieties adapted to future conditions, improve productivity and reduce malnutrition. Several studies in India on pearl millet, sorghum and groundnut mini core collections under drought, soil nutrients deficiency, heat, salinity and/or photoperiod conditions contributed to select diverse sources of several traits used in breeding new and performant varieties (Upadhyaya et al., 2001; Upadhyaya et al., 2003; Upadhyaya et al., 2008, Upadhyaya et al., 2012; Yadav et al., 2017; Kumar et al., 2012). Accessions ICG 12625, ICG 442, ICG 2381, ICG 14710 and ICG 7963 of groundnut (Upadhyaya et al., 2014), IP 4066, IP 9496 and IP 9426 of pearl millet (Yadav et al., 2003), and IS 2205, IS 3946, IS 5094 and IS 12883 of sorghum (Upadhyaya et al.,
2009; Mohankumar et al., 2013) were some of selected germplasm for release and/or used in breeding programs to improve productivity and nutrition quality in India. Climate shocks will likely have an overall negative effects on agricultural production in many African countries and regions, and this could lead to food insecurity and malnutrition exacerbation (IPCC, 2014). West Africa is known to be particularly vulnerable to climate change due to high climate variability, high reliance on rainfed agriculture, and limited economic and institutional capacity to respond to climate variability and change (Nelson et al., 2009; Sultan and Gaetani, 2016). Pearl millet, sorghum and groundnut are most important crops for food security and nutrition in West African countries (Hausmann et al. 2011, Vigouroux et al., 2011, Hamidou et al., 2012, Hamidou et al., 2013, Hamidou et al., 2014.) In Sahelian areas of West African regions groundnut, pearl millet and sorghum cultivation play key roles in food and nutrition but abiotic stresses particularly drought, heat, low soil fertility and malnutrition are yield and nutritive quality limiting constraints. These stresses will become more severe in near future and require identification of genotypes tolerant to abiotic stresses and relevant traits useful in breeding programs for improving adaptation, production and/or nutrition

*Author for Correspondence: Email- h.falalou@cgiar.org

Indian J. Plant Genet. Resour. 30(3): 201-209 (2017) 
quality of major crops cultivated in the Sahel (Sultan and Gaetani, 2016). Like in India, exploiting/investigating the mini core collections of groundnut, sorghum and pearl millet in Sahelian countries could lead to select genotypes tolerant to major abiotic stresses and highly rich in micronutrients for developing crop improvement strategies that favor adaptation to climate variability. This work aims to investigate response of groundnut, pearl millet and sorghum germplasm mini core collections (Upadhyaya et al., 2002, 2009, 2011) to drought and low soil phosphorus stresses. The objectives were to (i) characterize these germplasms under drought and/or low phosphorus conditions for selecting high yielding genotypes, (ii) assess individual and combined effects of drought and low phosphorus stress on agronomic performance and nutrients content of the germplasm and (iii) identify tolerant genotypes and relevant traits for crop improvement.

\section{Material and Methods}

Three experiments were conducted at the International Crop Research Institute for the Semi-Arid Tropics (ICRISAT), Sahelian Centre (ISC) in Sadoré (45 km south of Niamey, Niger, $13^{\circ} \mathrm{N}, 2^{\circ} \mathrm{E}$ ) during 2015 and 2016. Climatic data (temperature, humidity and ET through class A pan evaporation) were recorded daily from a meteorological station located close to the experiments. In addition, the temperature and relative humidity of the air were collected from a temperature and relative humidity recorder (Gemini Tinytag Ultra 2 TGU-4500 Data logger Ltd, Chichester, UK) located in the crop canopy.

One hundred and six (106) germplasm including 60 accessions of groundnut mini core collection (Upadhyaya et al., 2002), 25 accessions of pearl millet mini core collection (Upadhyaya et al., 2011) and 21 landraces of sorghum (Table 1) were assessed during rainy and off-seasons in lysimetre tubes $(25 \mathrm{~cm}$ diameter, $130 \mathrm{~cm}$ height). The lysimetric system was well described in our previous works (Beggi et al., 2014; Halilou et al., 2015). The soil used to fill the lysimetre tubes was collected from the farm in Sadoré station. The characteristics of the soil are: $\mathrm{pH}-\mathrm{H}_{2} \mathrm{O}$ (5.28), capacity of cation exchange $\left(1.91 \mathrm{cmol}+\mathrm{kg}^{-1}\right)$, organic matter $(0.22 \%)$, total nitrogen (204.3 mg-N kg-1), total phosphorus (26.25 mg-P kg-1), phosphorus brayl $\left(1,83 \mathrm{mg}-\mathrm{P} \mathrm{kg}^{-1}\right)$. Top soil $(0-20 \mathrm{~cm})$ and deep soil $(20-100 \mathrm{~cm})$ were collected separately from the farm. To mimic the field conditions, the lysimetre tubes were filled with deep soil ( $100 \mathrm{~cm}$ height) followed by top soil $(20 \mathrm{~cm}$ height). The upper $10 \mathrm{~cm}$ of the tubes was left empty to allow the application of a layer of anti-evaporation beads and for watering. Three seeds were sown by hand and seedlings were thinned to one plant per tube at 14 days after sowing (DAS). The experimental design was a randomized complete block design with 5 replications, 2 water regimes and 2 phosphorus treatments. The water regimes were a full irrigation (WW) until harvest and a drought stress (WS) imposed from flowering (50\%) to maturity times. WS was an intermittent drought consisting of cycles of drying (irrigation interruption) and re-watering $(1000 \mathrm{~mL}$ of water per tube) when the majority of WS plants showed clear wilting symptoms (Hamidou et al., 2012). Prior to imposing WS, the lysimetre tubes were water saturated, drained during 2 days to reach field capacity and the soil surface was covered with a $2 \mathrm{~cm}$ thick layer of polyethylene beads to minimize soil evaporation (Ratnakumar et al., 2009). The two phosphorus treatments were HP treatment consisting of applying $7.5 \mathrm{~g}$ DAP tube $^{-1}$ in a circle $2-3 \mathrm{~cm}$ around the seedling area after emergence and the LP treatment consisted of no application of phosphorus in the tubes but supply urea (3.45 g applied in two doses) to compensate nitrogen input from DAP applied in HP tubes. DAP and urea were used in these experiments because they are the common fertilizers used by Sahelian farmers. The phenology (Heading, flowering and maturity times), growth (height), total transpiration (TTW) and transpiration efficiency (TE), micronutrients content $(\mathrm{Fe}, \mathrm{Zn})$, yield and its components were some of parameters measured. For TE measurement, two plants were left per tube after thinning. The day before water stress imposition, one of 2 plants of each tube was harvested, dried at $70^{\circ} \mathrm{C}$ for 2 days and the initial biomass (IDM) was determined. During water stress period, transpiration was measured via a gravimetric procedure. Thus, lysimetre tubes were weighed regularly (twice per week). As there was no evaporation nor draining, the difference of consecutive lysimetre weights, plus water added after the previous weighing, was equivalent to the transpiration (Vadez et al., 2011a). The total transpired water (TTW) of WW and WS plants was determined for each individual plant. At maturity, plant of each cylinder was harvested, dried at $70^{\circ} \mathrm{C}$ for 2 days for determining the final dry matter (FDM). So, TE was calculated as: $\mathrm{TE}=(\mathrm{FDM}-$ mean IDM) /TTW. For the micronutrients (Fe, Zn) content 
Table 1. Names and origins of groundnut, pearl millet and sorghum germplasm. ISS $\mathbf{N}^{0}=$ ICRISAT Niamey genebank sorghum accession number. $\mathrm{RCA}=$ Republique Centre Africaine

\begin{tabular}{|c|c|c|c|c|c|c|c|c|c|}
\hline \multirow[b]{2}{*}{ No } & \multicolumn{4}{|c|}{ Groundnut germplasm } & \multicolumn{2}{|c|}{ Pearl millet germplasm } & \multicolumn{3}{|c|}{ Sorghum germplasm (landraces) } \\
\hline & Name & Origin & Name & origin & Name & Origin & Local Name & ISS No & Origin \\
\hline 1 & ICG 6813 & India & ICG 15233 & Unknown & IP19629 & Niger & Yarimawa & ISS 242 & Nigeria \\
\hline 2 & ICG 15232 & Unknown & ICG 11855 & Bolivia & IP5455 & Niger & Acualé & ISS 309 & NIGER \\
\hline 3 & ICG 36 & India & ICG 7897 & Zimbabwe & IP5719 & Nigeria & Zermou FDawa & ISS 311 & NIGER \\
\hline 4 & ICG 6201 & Unknown & ICG 5494 & Sudan & IP5964 & Senegal & $98-884$ & ISS 333 & Mauritanie \\
\hline 5 & ICG 7906 & Zimbabwe & ICG 3240 & Unknown & IP5869 & Senegal & $98-972$ & ISS 337 & Mauritanie \\
\hline 6 & ICG 6394 & Zimbabwe & ICG 1415 & Senegal & IP1060 & India & Betakatchi & ISS 376 & Tchad \\
\hline 7 & ICG 5195 & Kenya & ICG 7181 & USA & IP6517 & Mali & Méré Rafa & ISS 378 & Tchad \\
\hline 8 & ICG 10384 & Argentina & ICG 9666 & Mozambique & IP5581 & Niger & Socomba Tiudawa & ISS 705 & niger \\
\hline 9 & ICG 11542 & Korea & ICG 3775 & India & IP17532 & Togo & Socomba Gogueize & ISS 738 & niger \\
\hline 10 & ICG 10920 & Peru & ICG 334 & China & IP19415 & Chad & El Baoura & ISS 784 & niger \\
\hline 11 & ICG 9842 & Peru & ICG 1703 & Bolivia & IP5298 & Niger & Takanda Bagaroua & ISS 862 & niger \\
\hline 12 & ICG 3992 & Uganda & ICG 9777 & Mozambique & IP6113 & Niger & Jadawa Meguizawa & ISS 885 & niger \\
\hline 13 & ICG 6407 & Paraguay & ICG 9809 & Tanzania & IP5957 & Senegal & Gadiabablé & ISS 1148 & Mali \\
\hline 14 & ICG 1711 & Unknown & ICG 6703 & Senegal & IP6278 & Mali & Dérebléni & ISS 1350 & Mali \\
\hline 15 & ICG 15234 & Unknown & ICG 5475 & Malaysia & IP9000 & Niger & Gadiabakoumaba & ISS 1412 & Mali \\
\hline 16 & ICG 7969 & India & ICG 405 & Unknown & IP5438 & Niger & Kaurari K19-1 & ISS 2110 & Niger \\
\hline 17 & ICG 6022 & Cuba & ICG 2773 & India & IP5711 & Nigeria & Kaura Mai Sauri- & ISS 2148 & Niger \\
\hline 18 & ICG 4527 & Sudan & ICG 12276 & India & IP11405 & BFaso & Botsotsoia & ISS 2133 & Niger \\
\hline 19 & ICG 1142 & Benin & ICG 3746 & Brazil & IP5185 & Niger & Kaurari & ISS 2137 & Niger \\
\hline 20 & ICG 163 & Unknown & ICG 4746 & Malawi & IP17775 & Togo & Tantagaria & ISS 2151 & Niger \\
\hline 21 & ICG 10053 & Nigeria & ICG 81 & Unknown & IP6057 & $\mathrm{RCA}$ & Karangui & ISS 2167 & Niger \\
\hline 22 & ICG 1399 & Malawi & ICG 14475 & Mexico & IP8540 & India & & & \\
\hline 23 & ICG 1274 & Indonesia & ICG 1823 & Tanzania & IP5407 & Niger & & & \\
\hline 24 & ICG 1487 & USA & ICG 115 & India & IP5153 & Niger & & & \\
\hline 25 & ICG 10890 & Unknown & ICG 11088 & Taiwan & IP5261 & Niger & & & \\
\hline 26 & ICG 4670 & Israel & ICG 3312 & Argentina & & & & & \\
\hline 27 & ICG 6375 & Unknown & ICG 118 & India & & & & & \\
\hline 28 & ICG 10554 & Peru & ICG 12988 & Nigeria & & & & & \\
\hline 29 & ICG 11109 & China & ICG 862 & India & & & & & \\
\hline 30 & ICG 4911 & Sudan & ICG 3027 & Uganda & & & & & \\
\hline
\end{tabular}

of pearl millet and sorghum seeds, it was determined with XRF machine (Nielson et al., 1988).

\section{Results}

\section{Genotypic Variation in Response to Drought and/ or Low Phosphorus Stress}

\section{Groundnut Germplasm}

Flowering and maturity dates recorded on the groundnut mini core subset ranged from 22 to 31 and 85 to 97 days after sowing (DAS) respectively which indicate large genotypic variation. ICG 6703, ICG 7181, ICG 3775, ICG 6407 and ICG 10890 were the top 5 earliest maturing accessions while ICG 3027, ICG 15234, ICG 3992, ICG 9777 and ICG 9842 were late maturing materials. Significant genotype and water treatment interaction (GxTrt) was observed on the total transpired water (TTW) from flowering to maturity. TTW increased significantly under WS compared to WW for all accessions except ICG 1399, ICG 5494, ICG 1274, ICG 11542 and ICG 1142 which showed significant transpiration decrease due to WS. ICG 7181, ICG 10384, ICG 7906, ICG 163 and ICG 1711 revealed the highest TTW increase. ICG 3312 and ICG 11088 showed high TTW under both WW and WS regimes. The highest TTW under WW was observed on ICG 3312, ICG 11088, ICG 3746, ICG 862, ICG 1274, ICG 11542 and ICG 1399 while ICG 7181, ICG 36, ICG 163, ICG 10384 and ICG 6703 showed the lowest TTW. Under WS, the genotypic variation on TTW revealed that ICG 11855, ICG 115, ICG 11088, ICG 15233 and ICG 3312 had highest TTW whereas ICG 1142, ICG 5494, ICG 9777, ICG 6703 and ICG 10890 had the lowest. Transpiration efficiency (TE) investigated under WW and WS showed significant $(\mathrm{P}<0.001)$ effect of water regime and WS decreased TE up to $78 \%$. Significant $(\mathrm{P}<0.001)$ genotypic

Indian J. Plant Genet. Resour. 30(3): 201-209 (2017) 
variation was also observed under both WW and WS treatments, and ICG 9842, ICG 7181, ICG 3027, ICG 1274, ICG 14475 and ICG 4527 revealed high TE. Under WS, accessions with highest TE were ICG 3312 (1.85 $\left.\mathrm{g} \mathrm{kg}^{-1}\right)$, ICG $11088\left(1.61 \mathrm{~g} \mathrm{~kg}^{-1}\right)$, ICG 13395 (1.50 g $\left.\mathrm{kg}^{-1}\right)$ and ICG $4670\left(1.31 \mathrm{~g} \mathrm{~kg}^{-1}\right)$ and revealed tolerant to drought stress. Genotypic variation was also observed on the branch number per plant, the pod weight per plant (Pwpt), haulm weight per plant (Hwpt and seeds weight per plant (Swpt) which ranged respectively from 4 to $10,3.4 \mathrm{~g}$ to $19.4 \mathrm{~g}, 25 \mathrm{~g}$ to $55 \mathrm{~g}$ and $1.5 \mathrm{~g}$ to $15 \mathrm{~g}$. WS imposed at flowering time decreased Hwpt (30\%), Pwpt (68\%) and Swpt(71\%). Accessions ICG 3312, ICG 118, ICG 10053, ICG 15232 and ICG 11088 showed high pods and seeds weights under both WW and WS conditions. Linear regression performed showed high correlation $\left(\mathrm{r}^{2}=0.73\right)$ between TE and Hwpt whereas low correlation $\left(\mathrm{r}^{2}=0.26\right)$ was observed between Pwpt and TE under WS conditions (Fig. 1). Low phosphorus stress (LP) decreased the pod number per plant $(8 \%)$, the Pwpt (49\%) and Hwpt (31\%), the decrease due to combined WS and LP stress (WS-LP) was 16, 73 and $34 \%$ respectively. Under WS-LP conditions, ICG 4670 (4g) and ICG $3312(8 \mathrm{~g})$ showed lowest pods weight while ICG 3399 (11g), ICG 115 (13g) and 3746 (18g) revealed the highest Pwpt.

\section{Pearl Millet Germplasm}

Phosphorus treatment has significant effect on tillering times, tillers number per plant, heading/booting time, flowering time and plant height of pearl millet accessions. Under HP, heading and flowering times ranged respectively from 43 to $65 \mathrm{DAS}$ and 48 to 74 while under LP they ranged from 53 to 71 DAS and 57 to 75 DAS. LP delayed tillering, heading and flowering times while it decreased tillers number $(30 \%)$ and plant height $(22 \%)$. Heading and flowering delay due to LP ranged from 3 to 16 days and genotypic variation revealed that

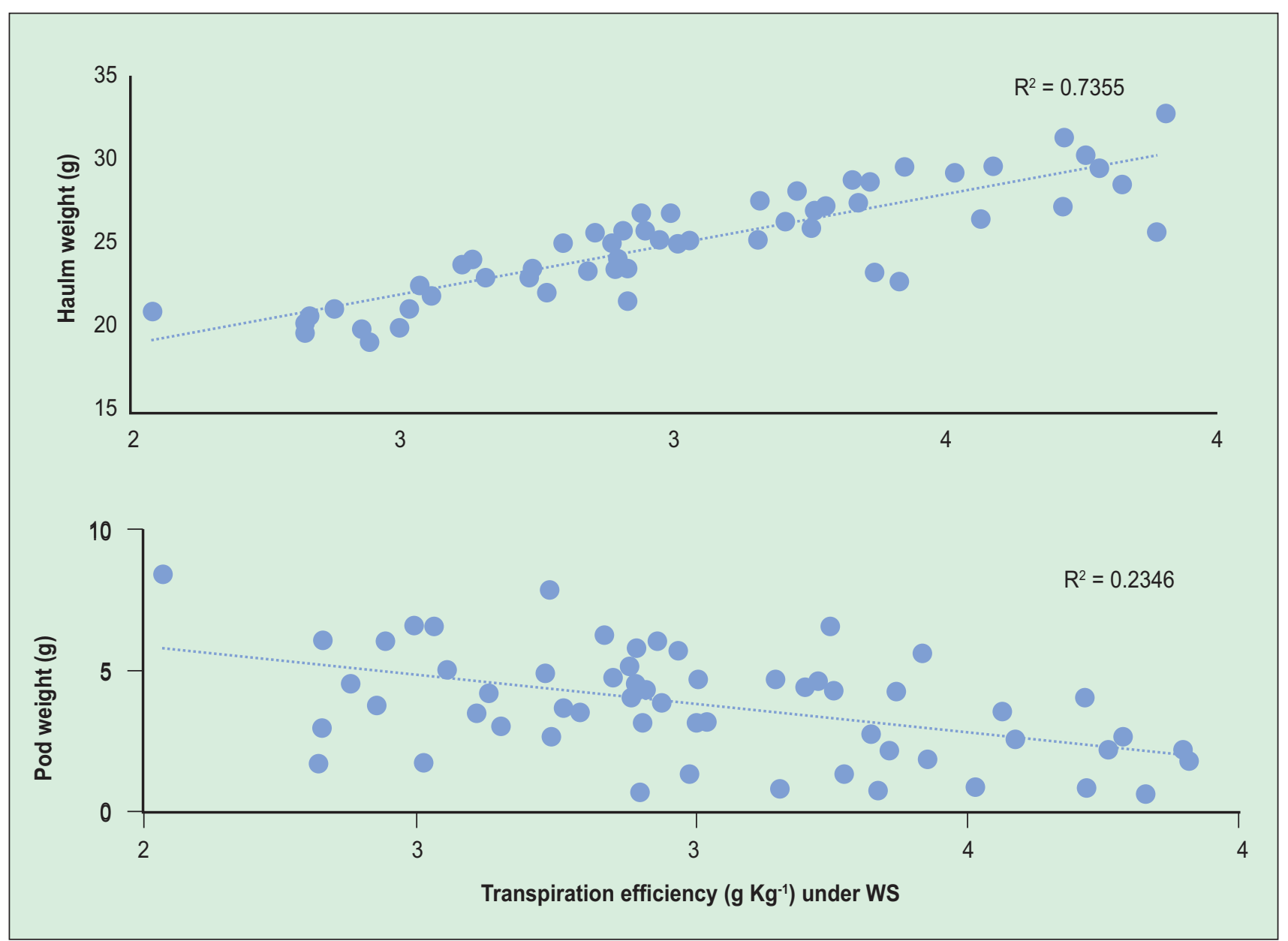

Fig. 1. Relationship between transpiration efficiency, pod and haulm weight per plant of groundnut germplasm under drought stress (WS) conditions

Indian J. Plant Genet. Resour. 30(3): 201-209 (2017) 
IP1060, IP11405, IP19629, IP5185, IP5455 and IP9000 had 4 days of delay whereas IP5298, IP5869, IP5964 and IP8540 delayed for 13 to 16 days. LP stress decreased the total biomass and panicle weight up to 37 and 56\% respectively. The highest biomass $(70 \mathrm{~g})$ was observed on IP19629, IP5298, IP5581, IP5719 and IP5407 whereas IP11405, IP17532, IP17775, IP5957 and IP6057 showed the lowest $(35 \mathrm{~g})$. The panicle weight under LP revealed highest values (15g) for IP1060, IP11405, IP5957, IP5964 and IP9000 and lowest values (2.6g) for IP5153, IP5185, IP5438, IP5711 and IP6517.

\section{Sorghum Germplasm}

Genetic diversity was observed on the phenology of sorghum accessions. Significant genotype and phosphorus treatment interaction was observed on heading, flowering and maturity times. Under HP and LP conditions heading time ranged respectively from 39 to 80 DAS and 44 to 82 DAS. Variation on flowering time was from 41 to 81 under HP and 46 to 87 DAS under LP whereas maturity time varied under HP and LP from 61 to 93 DAS and 60 to 107 DAS, respectively. Phosphorus deficiency (LP) had no significant effect on days to flowering and maturity in accessions ISS 1148, ISS 1412, ISS 2133, ISS 2167, ISS 376, ISS 705 and ISS 738 while it delayed flowering and maturity dates in ISS 2110 , ISS 2151, ISS 242, ISS 309 and ISS 337. Significant $(\mathrm{P}<0.001)$ genotypic difference was observed also on total biomass, panicle weight per plant (pawpt) and Swpt under both HP and LP treatments. Under LP, ISS 337 (80.6g), ISS 2110 (80.7g), ISS 2133 (81.6g), ISS 2151 (86.5g), ISS $1350(94.4 \mathrm{~g})$ and ISS 2137 (97.8g) showed the highest biomass, the highest pawpt observed on ISS 1350 (27.5g), ISS $1412(33.7 \mathrm{~g})$, ISS 2133 (32.5g), ISS 2137 (40g), ISS 2148 (27.6g) and ISS 337 (27.2g) while the highest Swpt was observed on ISS $2110(21.7 \mathrm{~g})$, ISS 1350 (22g), ISS 1412 (24.5g), ISS 2133 (24.6g), ISS $2137(30.3 \mathrm{~g})$ and ISS $2167(22.4 \mathrm{~g})$.

\section{Micronutrient Contents in Pearl Millet and Sorghum}

Determination of Iron ( $\mathrm{Fe})$ and zinc $(\mathrm{Zn})$ in seeds revealed significant $(\mathrm{P}<0.001)$ phosphorus treatment effect on $\mathrm{Fe}$ content in both pearl millet and sorghum (Fig. 2) while for $\mathrm{Zn}$ content the effect was significant $(\mathrm{P}=0.004)$ only in sorghum. Fe decrease due to LP was 25 and $13 \%$ in pearl millet and sorghum, respectively, $\mathrm{Zn}$ decrease in sorghum was $11 \%$. Genotypic variation in micronutrients contents showed that under HP conditions Fe content varied from 30 to $72 \mathrm{mg} \mathrm{kg}^{-1}$ in pearl millet, from 38 to $64 \mathrm{mg} \mathrm{kg}^{-1}$ in sorghum while under LP treatment Fe content ranged from 27 to $57 \mathrm{mg} \mathrm{kg}^{-1}$ in pearl millet and from 33 to $54 \mathrm{mg} \mathrm{kg-1}$ in sorghum. IP5261 (58 mg kg-1), IP5185 (63 $\left.\mathrm{mg} \mathrm{kg}^{-1}\right)$, IP5964 (64 mg kg-1), IP17775 (66 mg kg-1) and IP9000 (72 mg kg-1) for pearl millet and ISS $885\left(56 \mathrm{mg} \mathrm{kg}^{-1}\right)$, ISS $1148(60 \mathrm{mg}$ $\left.\mathrm{kg}^{-1}\right)$, ISS $2110\left(61 \mathrm{mg} \mathrm{kg}^{-1}\right)$, ISS $784\left(61 \mathrm{mg} \mathrm{kg}^{-1}\right)$ and ISS $242\left(64 \mathrm{mg} \mathrm{kg}^{-1}\right)$ for sorghum revealed the highest $\mathrm{Fe}$ concentrations. As for $\mathrm{Zn}$ content, the variation was from 38 to $96 \mathrm{mg} \mathrm{kg}^{-1}$ in millet and from 41 to $72 \mathrm{mg}$ $\mathrm{kg}^{-1}$ in sorghum under HP while under LP it ranged from 47 to $94 \mathrm{mg} \mathrm{kg}^{-1}$ in pearl millet and from 38 to $75 \mathrm{mg} \mathrm{kg}^{-1}$ in sorghum. Accessions IP17775 (49 mg kg-1), IP17532 (51 mg kg-1), IP5581 (51 mg kg-1) and IP5153 (57 mg kg-1) for pearl millet and ISS 333 (50 mg kg-1), ISS 376 (52 mg kg-1), ISS 311 (53 mg $\mathrm{kg}-1)$ and ISS 1412 (54mg kg-1) for sorghum revealed the highest Fe contents under LP conditions. Highest $\mathrm{Zn}$ contents in pearl millet under LP were observed on IP1060 (77 mg kg-1), IP6517 (82 mg kg-1), IP5438 (84 mg kg-1) and IP17775 (94 mg kg-1) and in sorghum on ISS 2167 (54 mg kg-1), ISS 242 (54 mg kg-1), ISS 311 (54 mg kg-1) and ISS 2151 (75 mg kg-1).

\section{Discussion}

\section{Drought and Low Phosphorus Tolerance in Groundnut}

The genetic variability observed on TTW suggests different water requirement and use among the groundnut accessions. In response to drought stress, some accessions like ICG 7181, ICG 10384, ICG 7906, ICG 163 and ICG 1711 increased TTW while others like ICG 1399, ICG 5494, ICG 1274, ICG 11542 and ICG 1142 decreased TTW. This suggests different mechanism of response to drought. Indeed, TTW increase under drought stress indicates an increase of water lost while TTW decrease shows a reduction of water lost. Jayant et al., 2015 reported that under drought stress, prevention of water loss through aerial parts of the plant is considered as one of the most important mechanism to avoid drought. Transpiration reduction in response to drought led to dehydration avoidance due to lower stomatal conductance in order to conserve water (Mafakheri et al., 2012). Accessions ICG 11855, ICG 115, ICG 11088, ICG 15233 and ICG 3312 showed the highest TTW under WS suggesting high stomatal conductance and intensive roots elongation to deeper part of the soil profile. High 


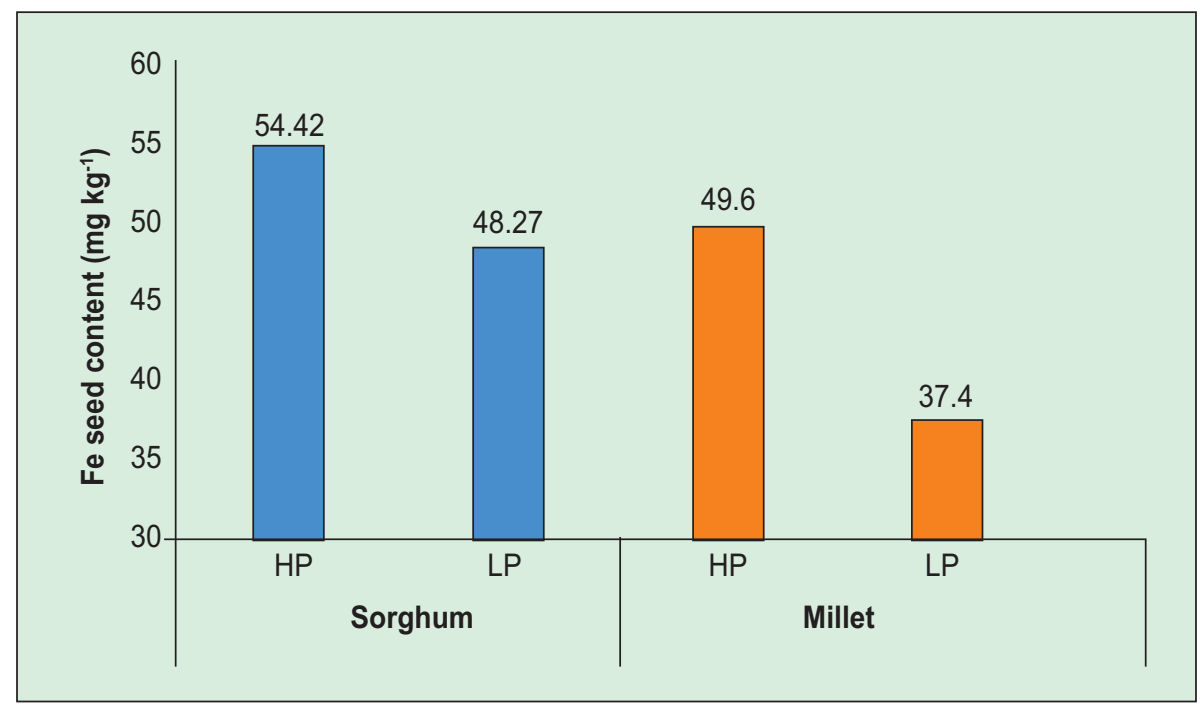

Fig. 2. Iron ( $\mathrm{Fe}$ ) content (mg kg-1) in pearl millet and sorghum seeds under high phosphorus (HP) and low Phosphorus (LP) conditions

transpiration under WS could reveal a drought tolerance mechanism by maintaining the turgor through osmotic adjustment, increase cell elasticity and decrease cell size as well as desiccation tolerance by protoplasmic resistance (Nemeskeri et al., 2012; Jacqueline et al., 2016).

The genotypic variation observed in TE revealed the highest TE on ICG $3312\left(1.85 \mathrm{~g} \mathrm{~kg}^{-1}\right)$, ICG 11088 $\left(1.61 \mathrm{~g} \mathrm{~kg}^{-1}\right)$, ICG $13395\left(1.50 \mathrm{~g} \mathrm{~kg}^{-1}\right)$ and ICG 4670 $\left(1.31 \mathrm{~g} \mathrm{~kg}^{-1}\right)$ under WS. The TE, calculated as dry matter produced per kg of water transpired, was highly correlated $\left(\mathrm{r}^{2}=0.73\right)$ to haulm weight under WS suggesting that canopy development contributed to TE. This corroborates previous works which reported that high TE under drought stress could be explained by specific leaf area, high roots dry matter and/or chlorophyll content (Puangbut et al., 2009a, Puangbut et al., 2009b). Drought stress decreased Pwpt and Swpt, the genotypic variation observed revealed that accessions ICG 3312 , ICG 11855, ICG 10053, ICG 15232 and ICG 11088 showed high Pwpt and Swpt under both WW and WS conditions. These accessions revealed high yielding and drought tolerant. They could be recommended for cultivation under rainfed environments and could be donors in groundnut improving programs for drought adaptation and productivity.

Low phosphorus (LP) stress had lower effect on Pwpt than WS. However, Pwpt decrease under WSLP stress $(73 \%)$ was higher than the decrease under individual WS (68\%) and LP (49\%) stress. ICG 3312 showed high Pwpt under WS and low Pwpt under WS-LP stress suggesting it was tolerant to drought but sensitive to combined WS-LP. These findings could indicate that phosphorus $(\mathrm{P})$ is much critical in pods productivity under drought stress in groundnut. Authors reported that $\mathrm{P}$ nutrient improved root traits to enhance tolerance to water stress and reduce yield loss in chickpea (Jin et al., 2012). ICG 115 which showed high TTW under WS conditions revealed high Pwpt under WS-LP stress suggesting a mechanism of roots elongation in deeper part of soil for exploring water and nutrients $(\mathrm{P})$ for tolerance to WS-LP.

\section{Low P Response and Nutrients Content in Pearl Millet and Sorghum}

In pearl millet, LP stress induced significant delay in heading and flowering dates. However, a genetic variability was observed indicating that accessions IP1060, IP11405, IP19629, IP5185, IP5455 and IP9000 showed 4 days of delay whereas the delay was up to 16 days for IP5298, IP5869, IP5964 and IP8540. Beggi et al. (2014) reported a booting and flowering delay up to 2 weeks due to LP stress in pearl millet. The genetic diversity observed could be exploited in breeding for LP tolerance in pearl millet. Phenological delay has often been reported as an adaptive response of annual plants to $\mathrm{P}$ deficiency because it increases the duration of nutrient uptake (Nord and Lynch, 2008). However, under Sahelian conditions where mid-season and terminal drought occur frequently, a flowering delay in pearl millet would indeed increase the risk of the plant 
encountering water deficient conditions. Our findings showed a biomass and panicle weight decrease due to LP stress. Accessions IP1060, IP11405 and IP9000 showed short delay and high panicle weight suggesting that no significant sensitivity of flowering time to LP stress could have benefits in grains productivity. In previous work (Beggi et al., 2014) we found high correlations between flowering delay and grains yield in pearl millet and had also observed that genotypes with short flowering delay under LP stress showed less decrease of seeds size. Thus, IP1060, IP11405 and IP9000 revealed interesting materials potentially useful for low soil $\mathrm{P}$ conditions and in breeding program for improving tolerance to LP stress.

Low soil $\mathrm{P}$ affected also the micronutrients content of seed in pearl millet. Fe content deceased up to $25 \%$ while the effect was not significant for Zn content. Large genotypic variation was observed on Fe content which ranged from 27 to $57 \mathrm{mg} \mathrm{kg}^{-1}$. Previous studies reported also a wide variability for $\mathrm{Fe}$ in pearl millet (Rai et al., 2008; Rai et al., 2012; Rai et al., 2014; Elad et al., 2015; Yadav et al., 2016; Yadav et al., 2017). With high Fe concentration, IP5261 (58 mg kg-1), IP5185 (63 mg $\left.\mathrm{kg}^{-1}\right)$, IP5964 (64 mg kg-1), IP17775 $\left(66 \mathrm{mg} \mathrm{kg}^{-1}\right)$ and IP9000 (72 $\left.\mathrm{mg} \mathrm{kg}^{-1}\right)$ revealed new sources of high Fe concentration and could be useful for biofortification program in pearl millet. Fe concentration of those lines was less high than in IP $17602\left(121 \mathrm{mg} \mathrm{kg}^{-1}\right)$, IP 17673 $\left(109 \mathrm{mgkg}^{-1}\right)$ and IP $9404\left(108 \mathrm{mg} \mathrm{kg}^{-1}\right)$ reported by Yadav et al. (2017). This difference could be explained by the soil type and/or soil nutrient contents. Accessions IP17775 (49 mg kg-1), IP17532 (51 mg kg-1), IP5581 $\left(51 \mathrm{mg} \mathrm{kg}^{-1}\right)$ and IP5153 $\left(57 \mathrm{mg} \mathrm{kg}^{-1}\right)$ showed high Fe content under LP conditions. These accessions revealed promising materials for low soil $\mathrm{P}$ environments. Highest $\mathrm{Zn}$ contents under LP were observed on IP1060 $(77 \mathrm{mg}$ $\left.\mathrm{kg}^{-1}\right)$, IP6517 (82 $\left.\mathrm{mg} \mathrm{kg}^{-1}\right)$, IP5438 (84 mg kg-1) and IP17775 (94 mg kg-1). Interestingly, IP17775 showed high $\mathrm{Fe}$ and $\mathrm{Zn}$ contents under LP stress suggesting it could contribute in food nutrition to combat $\mathrm{Fe}$ and $\mathrm{Zn}$ deficiency (Issoufou et al., 2013; Jakunti et al., 2016).

In Sorghum, large variation in phenology was observed. The flowering time varied from 41 to 81 DAS under HP and 46 to 87 DAS under LP whereas maturity time varied under HP and LP respectively from 61 to 93 DAS and 60 to 107 DAS. LP stress induced flowering and maturity delay on some accessions while it had no significant effect on others, which indicates genotypic variation in response to soil $\mathrm{P}$ deficiency. Delayed heading and flowering in west African sorghum panel under LP stress was reported previously (Leiser et al., 2014). The large delay in flowering under LP conditions indicates important growth differences which should permit a genetic study of adaptation to P-limited conditions. The absence of significant effect of LP stress on phenological traits of ISS 1148, ISS 1412, ISS 2133, ISS 2167, ISS 376, ISS 705 and ISS 738 could suggest tolerance to LP. Additional studies are required for confirmation and understanding the mechanisms underlying the non-significant effect of LP stress on the phenology plasticity of theses accessions. Under LP conditions, ISS 333 (50 mg kg-1), ISS 376 (52 $\left.\mathrm{mg} \mathrm{kg}^{-1}\right)$, ISS 311 (53 mg kg-1) and ISS $1412\left(54 \mathrm{mg} \mathrm{kg}^{-1}\right)$ showed high Fe content while high $\mathrm{Zn}$ concentration was observed on ISS 2167 (54 $\left.\mathrm{mg} \mathrm{kg}^{-1}\right)$, ISS $242\left(54 \mathrm{mg} \mathrm{kg}^{-1}\right)$, ISS $311\left(54 \mathrm{mg} \mathrm{kg}^{-1}\right)$ and ISS $2151\left(75 \mathrm{mg} \mathrm{kg}^{-1}\right)$. ISS 311 with high $\mathrm{Fe}$ and $\mathrm{Zn}$ contents under LP stress could contribute in food nutrition to alleviate $\mathrm{Fe}$ and $\mathrm{Zn}$ deficiency but bioavailability of these micronutrients must be confirmed.

\section{References}

Beggi F, F Hamidou, A Buerkert and V Vadez (2014) Tolerant pearl millet (Pennisetum glaucum (L.) R. Br.) varieties to low soil $\mathrm{P}$ have higher transpiration efficiency and lower flowering delay than sensitive ones. Plant and soil 389: 89-108.

Elad T, MR Spenser, Budiman J, JH Jonathan and RP Glahn (2015) Higher iron pearl millet (Pennisetum glaucum L.) provides more absorbable iron that is limited by increased polyphenolic content. Nutrition Journal 14: 1-9.

Halilou O, F Hamidou, TB Katzelma, S Mahamane and V Vadez (2015) Water use, transpiration efficiency and yield in cowpea (Vigna unguiculata (L.) Walp) and peanut (Arachis hypogaea L.) across water regimes. Crop \& Pasture Science 66: 715-728.

Hamidou F, P Ratnakumar, O Halilou, O Mponda, T Kapewa, E Monyo, I Faye, B Ntare, SN Nigam, HD Upadhyaya and V Vadez (2012) Selection of intermittent drought stress tolerant lines across years and locations in the reference collection of groundnut (Arachis hypogaea L.). Field Crops Res. 126:189-199.

Hamidou F, O Halilou and V Vadez (2013) Assessment of groundnut under combined heat and drought stress. J. of Agro. and Crop Sci. 199: 1-11.

Hamidou F, A Rathore, F Waliyar and V Vadez (2014) Although drought intensity increases aflatoxin contamination, drought tolerance does not lead to less aflatoxin contamination. Field Crops Res. 156: 103-110.

Haussmann BIG, HF Rattunde, E Weltzien-Rattunde, PSC Traore', K vom Brocke and HK Parzies (2011) Breeding 
strategies for adaptation of pearl millet and sorghum to climate variability and change in west Africa. J. Agro. Crop Sci. doi:10.1111/j.1439-37X.2012. 00526.x

IPCC (2014) Climate Change 2014: Impacts, Adaptation, and Vulnerability. Part B: Regional Aspects. Contribution of Working Group II to the Fifth Assessment Report of the Intergovernmental Panel on Climate Change. (V. R. Barros, C. B. Field, D. J. Dokken, M. D. Mastrandrea, K. J. Mach, T. E. Bilir, L. L. White, Eds.) Cambridge, United Kingdom and New York, NY, USA: Cambridge University Press.http:// www.ejfa.info/ 501

Issoufou A, EG Mahamadou and GW Le (2013) Millets: Nutritional composition, some health benefits and processing - A Review. Emir. J. Food Agric. 7: 501-508.

Jacqueline WLP, MB Albuquerque, PAM Filho, RJMC NLM de Lima and RC Santos (2016) Assessment of drought tolerance of peanut cultivars based on physiological and yield traits in a semiarid environment. Agricultural Water Management 166: 70-76.

Jayant KS and SK Sarangi (2015) Effect of drought stress on epicuticular wax load in peanut genotypes. Journal of Applied Biology \& Biotechnology 3: 046-048.

Jin J, W Guanghua and L Xiaobing (2012) Phosphorus nutrition affects root morphology response to water deficit at different reproductive stages in an early soybean cultivar. $h t t p: / / w w w$. regional.org.au/au/asa.

Ukanti AKJ, CLL Gowda, KN Rai, VK Manga and RK Bhatt (2016) Crops that feed the world. Pearl Millet (Pennisetum glaucum L.): an important source of food security, nutrition and health in the arid and semi-arid tropics. Food Sec., DOI 10.1007/s12571-016-0557-y

Kumar AA, BVS Reddy, B Ramaiah, KL Sahrawat and WH Pfeiffer (2012) Genetic variability and character association for grain iron and zinc contents in sorghum germplasm accessions and commercial cultivars. The European Journal of Plant Science and Biotechnology 6: 1-5.

Leiser WL., HFW Rattunde, E Weltzien, C Ndiaga, A Magagi, A Diallo, A O Tourè, JV Magalhaes and BIG Haussmann( 2014) Two in one sweep: aluminum tolerance and grain yield in P-limited soils are associated to the same genomic region in West African Sorghum. BMC Plant Biol. 14:1-13.

Mohankumar HK, P Ramasamy, D Maduraimuthu, MA Robert., T Tesfaye, PPV Vara and RL, Christopher (2013) Genotypic variation in sorghum [Sorghum bicolor (L.) Moench] exotic germplasm collections for drought and disease tolerance. SpringerPlus 2:650. doi:10.1186/2193-1801-2-650.

Mafakheri A, A Siosemardeh, B Bahramnejad, PC Struik and Y Sohrabi (2012) Effect of drought stress on yield, proline and chlorophyll contents in three chickpea cultivars. AJCS 8: $580-585$.

Nelson GC, MW Rosegrant, J Koo, R Robertson, T Sulser, T Zhu, C Ringler, S Msangi, A Palazzo, M Batka, M Magalhaes, R Valmonte-Santos, M Ewing and D Lee (2009) Climate Change impact on agriculture and costs of adaptation. International Food Policy Research Institute, Food Policy Report. Washington, District of Columbia, $30 \mathrm{p}$.
Nielson KK, AW Mahoney and VC Rogers (1988) X-ray Fluorescence and Atomic Absorption Spectrophotometry measurements of manganese, iron, copper and zinc in selected foods. J. Agric. Food Chem. 36: 1211-1216.

Nord EA and JP Lynch (2008) Delayed reproduction in Arabidopsis thaliana improves fitness in soil with suboptimal phosphorus availability. Plant Cell Environ 31:1432-1441.

Puangbut D, S Jogloy, N Vorasoot, C Akkasaeng, T Kesmala and A Patanothai (2009) Variability in yield responses of peanut (Arachis hypogaea L.) genotypes under early season drought. Asian J Plant Sci. 8: 254-264.

Puangbut D, S Jogloy, N Vorasoot, C Akkasaeng, T Kesmala, RCN Rachaputi, Wright GC and A Patanothai (2009) Association of root dry weight and transpiration efficiency of peanut genotypes under early season drought. Agr Water Manage. 96: 1460-1466

Rai KN, CLL Gowda, BVS Reddy and S Sehgal (2008) The potential of sorghum and pearl millet in alternative and health food uses. Comprehensive Reviews in Food Sci. and Food Safety 7: 340-352.

Rai KN, M Govindaraj and AS Rao (2012) Genetic enhancement of grain iron and zinc content in pearl millet. Quality Assurance \& Safety of Crops and Food 4: 119-125.

Rai KN, HT Patil, OP Yadav, M Govindaraj, IS Khairwal, B Cherian, BS Rajpurohit, AS Rao, H Shivade and MP Kulkarni (2014) Dhanashakti: A high-iron pearl millet variety. Indian Farming 7: 32-34.

Ratnakumar P, V Vadez, SN Nigam and L Krishnamurthy (2009) Assessment of transpiration efficiency in peanut (Arachis hypogaea L.) under drought by lysimetric system. Plant Biol. 11: 124-130.

Sultan B and G Marco (2016) Agriculture in West Africa in the twenty-first century: Climate change and impacts scenarios and potential for adaptation. Frontiers in Plant Science 7: 1-20.

Upadhyaya HD, SL Dwivedi, RK Varshney, DA Hoisington and CLL Gowda (2008) Using genetic and genomic resources to broaden the genetic base of cultivated groundnut. In: Abstract Book. AAGB 2008. 3rd International Conference of the Peanut Research Community on Advances in Arachis through Genomics and Biotechnology, November 4-8, 2008. ICRISAT, Hyderabad, Andhra Pradesh, India, 6p

Upadhyaya HD, RPS Pundir, SL Dwivedi, CLL Gowda, VG Reddy and S Singh (2009) Developing a minicore collection of sorghum for diversified utilization of germplasm. Crop Sci. 49:1769-1780.

Upadhyaya HD and R Ortiz (2001) A mini core collection for capturing diversity and promoting utilization of chickpea genetic resources in crop improvement. Theor. Appl. Genet. 102: 1292-1298.

Upadhyaya HD, D Yadav, KN Reddy, CLL Gowda and S Singh (2011) Development of pearl millet mini core collection for enhanced utilization of germplasm. Crop Sci. 51: 217223.

Upadhyaya HD, KN Reddy, MI Ahmed, N Dronavalli and CLL Gowda (2012b) Latitudinal variation and distribution

Indian J. Plant Genet. Resour. 30(3): 201-209 (2017) 
of photoperiod and temperature sensitivity for fl owering in the world collection of pearl millet germplasm at ICRISAT genebank. Plant Genet. Resour. Characterization Utilization 10: $59-69$.

Upadhyaya HD, PJ Bramel, R Ortiz and S Singh (2002) Developing of a mini core of peanut for utilization of genetic resources. Crop Sci. 42: 2150-2156.

Upadhyaya HD, SL Dwivedi, V Vadez, F Hamidou, S Singh, RK Varshney and B Liao (2014) Multiple resistant and nutritionally dense germplasm identified from mini core collection in peanut. Crop Sci. 54: 1-15. doi: 10.2135/ cropsci2013.07.0493

Vadez, V., SP Deshpande, J Kholova, G.L Hammer, AK Borrell, HS Talwar and CT Hash (2011) Stay-green quantitative trait loci's effects on water extraction: transpiration efficiency and seed yield depend on recipient parent background. Funct. Plant Biol. 38: 553-566.
Vigouroux Y, C Mariac, S De Mita, JL Pham, B Gerard, I Kapran, F Sagnard, M Deu, J Chantereau, AAli, J Ndjeunga, V Luong, AC Thuillet, AA Saidou and G Bezanson (2011) Selection for earlier flowering crop associated with climatic variations in the Sahel. PLOS ONE 6: e19563. [www.plosone.org].

Yadav OP, E Weltzien-Rattunde and FR Bidinger (2003) Genetic variation for drought response among landraces of pearl millet (Pennisetum glaucum). Indian J. Genet. 63: 37-40.

Yadav OP, KN Rai, HP Yadav, PS Rajpurohit, SK Gupta, A Rathore and CG Karjagi (2016) Assessment of diversity in commercial hybrids of pearl millet in India. Indian J. of Plant Genet. Resour. 29: 130-136.

Yadav OP, Upadhyaya HD, Reddy KN, Jukanti AK, Pandey Sushil and Tyagi RK (2017) Genetic resources of pearl millet: Status and Utilization. Indian $J$ of Plant Genet. Resour. 30: 31-47. 